\title{
Protective effects of lycopene on oxidative stress, proliferation and autophagy in iron supplementation rats
}

\author{
Chongbin Liu *, Rui Wang, Bo Zhang, Chen Hu and Hong Zhang \\ Department of Physiology, Basic Medical Science Building, Huzhou Normal College, 313000, Huzhou, People's Republic of China
}

\begin{abstract}
Lycopene is common in diet and known for its antioxidant activities. However, the impact of lycopene on iron metabolism is poorly investigated. In this study, we hypothesize that lycopene can prevent iron-mediated oxidative stress, proliferation and autophagy in liver and use a rat model of nutritional iron supplementation to confirm its intervention in these defence mechanisms. We found that iron supplementation induced cell proliferation predominantly in non parenchymal cells compared with hepatocytes, but not apoptosis. In addition, iron was accumulated within the hepatic lysosomes where it triggered autophagy as evidenced by the formation of autophagic vesicles detected by LC3-B staining. Iron supplementation also induced morphologic alterations of the mitochondrial membranes probably due to increased lipid peroxidation as indicated by elevated iron and malondialdehyde concentrations in serum and tissues. Lycopene reduced iron-catalyzed lipid peroxidation by decreasing the malondialdehyde level in the liver and colon and enhancing the total superoxide dismutase activities in serum and tissues. The result suggest that lycopene prevents iron-induced oxidative stress, proliferation and autophagy at both biochemical and histological levels due to its potent free radical scavenging and antioxidant properties.
\end{abstract}

Key Terms: Autophagy, iron supplementation, lycopene, oxidative stress, proliferation

\section{INTRODUCTION}

Iron is an essential element for microbes, plants and higher animals. It is a component of heme and iron-sulphur centers in many key redox enzymes, and is an essential component of oxygen storage and transporting proteins such as haemoglobin and myoglobin (Andrews, 1999). It is also an integral part of several classes of enzymes involved in the synthesis of steroid hormones, detoxification of foreign substances in the liver, synthesis of neurotransmitters and DNA synthesis and breakdown (Garrick, 2011). In all species, the concentration of iron in biological fluids is tightly regulated to provide iron as needed and to avoid toxicity, because iron excess can lead to the generation of reactive oxygen species (ROS) by catalyzing the Fenton reaction and highly generates reactive hydroxyl radicals, which can damage the lipid membranes, proteins and nucleic acids (Eaton and Qian, 2002; Gao et al., 2009). Iron overload caused by frequent blood transfusions, high red meat consumption, and intake of iron supplements or caused by the genetic disorder hereditary hemochromatosis can promote troubles in many organs, mainly in the liver, which is the major location for iron storage (Andrews and Schmidt, 2007; Nahdi et al., 2010). Hepatic iron deposits and changes induced by this metal could be detected by electron microscopy based on the electron-dense iron content (Iancu, 2011). Hepatocyte alterations are promoted by different mechanisms: apoptosis, autophagy and necrosis (Galluzzi et al., 2007). Some studies also argued that, in situation of iron overload when ferritin may be iron-saturated, lysosomal destabilization is thought to be an adaptive response to provide the supply of energy needed for cell survival and repair induced by environmental stress (Garner et al., 1997; Kurz et al., 2007). In these last decades, there was growing interest in the association of specific components of human nutrition and oxidative stress (Morihara et al., 2006; Dairam et al., 2008). Lycopene, a carotenoid compound, occurring naturally in tomato and other fruits like papaya, pink guava and watermelon has been shown to neutralize free radicals, especially those derived from oxygen, thereby conferring protection against cancer of the prostate, breast, lung, bladder, cervix and skin, atherosclerosis and associated coronary artery disease (Sharma and Goswami, 2011). Dietary intakes of cooked tomatoes and their by-products account for $90 \%$ of the lycopene in the average Southern and North American diet (Bose and Agrawal, 2007; Garciaalonso et al., 2007). However, the impact of lycopene, known for its anti-cellproliferative, anticarcinogenic and antiatherogenic activities, on iron metabolism has been poorly understood.

In the present work, we hypothesized that lycopene could prevent iron-induced oxidative damage. We investigated the effects of chronic administration of different doses of lycopene on systemic iron status in rats fed with a normal or iron supplementation diet. Our aim was to determine whether iron supplementation associated with lycopene consumption promoted liver protection of rats. At the same time, our study was designed to evaluate the degree of damage induced by iron and determine the early defence mechanisms developed by hepatocytes with special attention to proliferation, apoptosis and autophagy, and to determine if the antioxidant effect of lycopene can be observed at the ultrastructure level and participate in these defence mechanisms.

List of abbreviations: BC, bile canaliculus; DAB, diaminobenzidine; DMT1, divalent metal transporter 1; LYS, lysosomes; M, mitochondria; MDA, malondialdehyde; NBT, nitrobluetetrazolium; PBS, phosphate-buffered saline; PMS, post mitochondrial supernatant; RER, rough endoplasmic reticulum; ROS, reactive oxygen species; TIBC, total iron-binding capacity; T-SOD, total superoxide dismutase.

*Correspondence: Chongbin Liu: liuchongbin1972@126.com. Tel: +86-572-2321201; Fax: +86-572-2321203

E-mail addresses for all authors: C.B. Liu, liuchongbin1972@126.com; R. Wang, wangrui1593@163.com; B. Zhang, zhangbo88@hutc.zj.cn; C. Hu, chenillehu@163.com; H. Zhang, zhanghong@hutc.zj.cn

Received: January 14, 2013. In Revised form: May 6, 2013. Accepted: May 7, 2013 


\section{METHODS}

\section{Chemicals}

Serum iron, total iron-binding capacity (TIBC), malondialdehyde (MDA) contents and the total superoxide dismutase (T-SOD) activities in tissues were quantified using commercial kit (Jiancheng Biological Engineering Company, Nanjing, China). Lycopene was purchased from Sigma (St. Louis, USA). The mouse Ki-67 monoclonal antibody (a cellular marker for proliferation), the mouse caspase-3 monoclonal antibody (a member of the apoptosis) and rabbit microtubuleassociated protein (LC3-B) polyclonal antibody were used (Biyuntian Biological Engineering Company, Shanghai, China). They were also processed for immunohistochemical analysis and electron microscopy. Other chemicals used in the present study were of analytical grade and were purchased from Sigma (St. Louis, USA).

\section{Animals and diets}

Thirty-six adult male Wistar rats $(220$ - $245 \mathrm{~g})$ were procured from the Central Animal House of the College (Wenzhou, China). The animals were housed in stainless steel cages, and maintained in a controlled environment under hygienic conditions of temperature $\left(25 \pm 2{ }^{\circ} \mathrm{C}\right)$, relative humidity of $40 \%$, and light (12-hour light/dark cycle, lights on 0700-1900). The rats were allowed to acclimatize in the animal facility for a period of 1 week before the beginning of the study. During that period of time, they had free access to standard animal diet and water ad libitum. All the procedures were performed in accordance with ethical guidelines on the care and use of animals in laboratory research which were approved by the Institutional Animal Ethics Committee (IAEC). The diet used during the experiment was prepared by thoroughly mixing the ingredients and chemical compounds (Table I) to obtain a homogeneous paste that was dried at $45{ }^{\circ} \mathrm{C}$, sliced and stored at $4{ }^{\circ} \mathrm{C}$ for a short time. The basal diet contained $50 \mathrm{mg} / \mathrm{kg}$ diet as ferrous sulfate $\left(\mathrm{FeSO}_{4} \cdot 7 \mathrm{H}_{2} \mathrm{O}\right)$. This iron supply corresponds to the recommended supply in growing rats and is slightly lower than the recommended supplies in humans (Nahdi et al., 2010). For the iron-treated group, this diet was supplemented with $1000 \mathrm{mg} / \mathrm{kg}$ diet. According to the rat's body weight, animals were intragastric administered lycopene dissolved in corn oil or $0.9 \%$ saline solution for 6 weeks (Kaur et al., 2011).

\section{Experimental protocol}

Rats were weighed and randomly allocated into six groups of six individuals: control group (received the basal diet and was fed distilled water by gavage at nine every day), iron group (received the basal diet supplemented with ferrous sulfate $1000 \mathrm{mg} / \mathrm{kg}$ diet and was fed distilled water by gavage at nine every day), lycopene group (received the basal diet and was given lycopene dissolved in corn oil by gavage at nine every day, at a dose of $15 \mathrm{mg} / \mathrm{kg}$ body weight), iron + lycopene groups (received the basal diet supplemented with ferrous sulfate $1000 \mathrm{mg} / \mathrm{kg}$ diet and was given lycopene dissolved in corn oil by gavage at nine every day, at doses of 20, 15 and $10 \mathrm{mg} / \mathrm{kg}$ body weight respectively). The rats received a fixed amount of food every day, and the remaining food was weighed to calculated the daily food intake per group. Sacrifice of all the group's rats was done 6 weeks after the beginning of the treatments. The rats were weighed, anesthetized by $10 \%$ chloral hydrate (intraabdominally), and killed. Blood was immediately collected and centrifuged at $3000 \times g$ for $15 \mathrm{~min}$. Serum was stored frozen at $-20{ }^{\circ} \mathrm{C}$ until use. The liver, heart, spleen, colon and kidney were dissected out, weighed and sectioned, and then tissue fragments were kept at $-80{ }^{\circ} \mathrm{C}$. The liver fragments were fixed in $4 \%$ polyoxymethylene followed by routine paraffin embedding and stained with hematoxylineosin for routine evaluation. They were also processed for immunohistochemical analysis and electron microscopy.

Evaluation of iron status

Serum iron concentrations and total iron-binding capacity (TIBC) were quantified using commercial kit, according to manufacture's instructions. The tissue iron contents were determined by acid digestion of tissue samples as described previously (Lyoumi et al., 2007; Nahdi, 2010), followed by iron quantification using a commercial kit, according to manufacture's instructions.

\section{Markers of oxidative stress}

Tissue homogenate $(10 \% \mathrm{~W} / \mathrm{V})$ was prepared in $50 \mathrm{mM}$ phosphate-buffered saline (PBS) using potter-Elvehjemtype glass homogenizer. The homogenate was centrifuged at 2000 $\times g$ for $15 \mathrm{~min}$ at $4{ }^{\circ} \mathrm{C}$. The content of malondialdehyde (MDA) was determined using a commercial kit. Briefly, the amount of MDA was measured by the reaction with thiobarbituric acid at $532 \mathrm{~nm}$. The results were expressed as nmoles MDA/

TABLE I

Ingredient composition of the basal diet fed to rats during the experimental period

\begin{tabular}{cc}
\hline Ingredients & Content ( g/kg diet) \\
\hline Corn flour & 270 \\
Bran & 190 \\
Rice & 160 \\
Soybean cake & 160 \\
Fish flour & 130 \\
$\mathrm{CaCO}_{3}$ & 20 \\
Bone dust & 30 \\
Yeast powder $^{\mathrm{NaCl}}$ & 22.5 \\
Vitamine mixture $^{\mathrm{a}}$ & 5 \\
Mineral mixture $^{\mathrm{b}}$ & 10 \\
FeSO $_{4}$ & 2.3 \\
\hline
\end{tabular}

a Vitamin mixture (unit/kg of mixture): synthetic vitamin A concentrate = $250,000 \mathrm{UI}$; cholecalciferol $=50,000 \mathrm{UI}$; -tocopherolacetate $=0.100 \mathrm{~g}$; thiamin hydrochloride $=0.100 \mathrm{~g}$; riboflavin sodium phosphate $=0.075 \mathrm{~g}$; pyridoxine hydrochloride $=0.100 \mathrm{~g}$;

ascorbic acid $=2.500 \mathrm{~g}$; nicotinamide $=0.500 \mathrm{~g}$; dexpanthenol $=0.200 \mathrm{~g}$.

b Mineral mixture (g/100 g mineral salt): $\mathrm{MgSO}_{4} \cdot 7 \mathrm{H}_{2} \mathrm{O}=73.82 ; \mathrm{ZnSO}_{4} \cdot 7 \mathrm{H}_{2} \mathrm{O}=$ 19.66; $\mathrm{MnSO}_{4} \cdot \mathrm{H}_{2} \mathrm{O}=4.22 ; \mathrm{CuSO}_{4} \cdot 5 \mathrm{H}_{2} \mathrm{O}=0.73 ; \mathrm{KIO}_{3}=0.06 ; \mathrm{Na}_{2} \mathrm{SeO}_{3}=0.9$ 
mg protein using molar extinction coefficient of MDAthiobarbituric acid chromophore. Protein concentration in supernatants was measured using Bradford method (Bradford, 1976; Nahdi et al., 2010). The total superoxide dismutase (T-SOD) activity in tissues was also quantified using a commercial kit according to the manufacture's instructions. Briefly, the reaction was initiated by the addition of hydroxylamine hydrochloride to the reaction mixture containing nitrobluetetrazolium (NBT) and post mitochondrial supernatant (PMS). The enzyme activity was measured at 560 $\mathrm{nm}$ and expressed as units/mg protein, where one unit of enzyme was defined as the amount of enzyme inhibiting the rate of a reaction by $50 \%$.

\section{Histology and immunohistochemistry}

Paraffin sections at $4 \mu \mathrm{m}$ were stained with Perls' Prussian Blue method for iron visualization. In the immunohistochemistry analysis, paraffin sections were incubated for $20 \mathrm{~min}$ in an autoclave at $95{ }^{\circ} \mathrm{C}$ in citric buffer $(0.01 \mathrm{M}, \mathrm{pH}$ 6.0) and left to cool for $20 \mathrm{~min}$ at room temperature. The slices were washed with phosphate-buffered saline (PBS) $(0.01 \mathrm{M}, \mathrm{pH} 7.4)$ before incubating in $0.6 \% \mathrm{H}_{2} \mathrm{O}_{2}$ for $20 \mathrm{~min}$ to quench the endogenous peroxidase activity. Then, the slices were incubated overnight at $4{ }^{\circ} \mathrm{C}$ with the mouse anti-active caspase- 3 monoclonal antibody (1:50), the mouse anti-Ki-67 monoclonal antibody (1:100) or the rabbit LC3-B polyclonal antibody (1:200) according to the manufacturer's recommendations. The slices were then washed three times with PBS for $10 \mathrm{~min}$. Biotinylated goat anti-mouse secondary antibody was used at a dilution of 1:200 in $60 \mathrm{~min}$ incubation at $37^{\circ} \mathrm{C}$. The antigenantibody complexes were stained with diaminobenzidine $(\mathrm{DAB})$ as chromogen, which generated a brown colour. Sections were counterstained with hematoxylin for $5 \mathrm{~min}$ and mounted in a mounting medium (Dako). Negative controls were run in parallel by replacing the primary antibody with non-immune immunoglobulins. Sections were observed using an Olympus DP70 microscope with DP-controller set to the same parameters. The number of caspase- 3 and Ki-67 positive cells was counted in 100 fields per group of rats, in order to detect apoptotic and proliferative cells respectively. The results were expressed as number of labelled cells $/ \mathrm{mm}^{2}$. LC3-B immunostaining was performed for detection of autophagy in hepatocytes.

\section{Electron microscopy}

Liver sections were fixed in $2.5 \%$ glutaraldehyde in cacodylate buffer $(0.1 \mathrm{M}, \mathrm{pH} 7.4)$, postfixed in a $1 \%$ osmium tetroxide solution, and embedded in Epon 812 resin. Ultra-thin sections were observed on a H-7500 transmission electron microscope (Hitachi in Japan) after lead citrate and uranyl acetate contrast. Some ultra-thin sections were not contrasted in order to visualize iron deposits in tissue.

\section{Statistical analysis}

Results were expressed as the mean \pm SD of six animals per group. Statistical analysis were performed using SPSS 16.0 for Windows (SPSS, Chicago, USA). Statistical differences were calculated using a one-way analysis of variance (ANOVA), followed by LSD's post hoc test. Statistical significance was defined as a $P$ value of less than 0.05 .

\section{RESULTS}

Effect of lycopene and lor iron supplementation on body weight and food intake

At the end of the 6 weeks treatment, the body weights of all rats were increased. There was no significant difference in body weight in the iron supplementation, lycopene and iron supplementation + lycopene groups versus the control rats despite the elevated food intake $(P<0.05)$ of treated animals compared with the controls. However, in the last 2 weeks, the weight gain of the iron supplementation group increased but less $(P<0.05)$ than that of the combined group (iron supplementation + mean lycopene). Indeed, food intake was higher $(P<0.05)$ in the iron supplementation + mean lycopene treated rats than in the iron supplementation rats (Table II).

TABLE II

The weight evaluation and total food intake in animals

\begin{tabular}{llllllllc}
\hline \multicolumn{1}{c}{$\begin{array}{c}\text { Groups } \\
(\mathbf{n}=\mathbf{6})\end{array}$} & Week 0 & Week 1 & Week 2 & Week 3 & Week 4 & Week 5 & Week 6 & $\begin{array}{c}\text { Total food intake } \\
\text { (g) }\end{array}$ \\
\hline Control & $231 \pm 8$ & $288 \pm 11$ & $325 \pm 10$ & $343 \pm 7$ & $368 \pm 12$ & $379 \pm 13$ & $388 \pm 10$ & $1032 \pm 146$ \\
Iron & $228 \pm 10$ & $278 \pm 8$ & $310 \pm 13$ & $327 \pm 10$ & $357 \pm 15$ & $366 \pm 13$ & $378 \pm 14$ & $1282 \pm 152^{\mathrm{a}}$ \\
Lycopene & $236 \pm 8$ & $285 \pm 12$ & $315 \pm 16$ & $339 \pm 11$ & $352 \pm 11$ & $370 \pm 8$ & $389 \pm 11$ & $1288 \pm 145^{\mathrm{a}}$ \\
Iron +High lycopene & $239 \pm 11$ & $283 \pm 9$ & $316 \pm 9$ & $332 \pm 14$ & $350 \pm 13$ & $362 \pm 15$ & $381 \pm 13$ & $1309 \pm 151^{\mathrm{a}}$ \\
Iron+Mean lycopene & $236 \pm 13$ & $283 \pm 15$ & $323 \pm 10$ & $340 \pm 10$ & $363 \pm 10$ & $382 \pm 11^{\mathrm{b}}$ & $402 \pm 12^{\mathrm{b}}$ & $1377 \pm 133^{\mathrm{a}, \mathrm{b}}$ \\
Iron+Low lycopene & $233 \pm 6$ & $284 \pm 8$ & $313 \pm 14$ & $333 \pm 9$ & $344 \pm 10$ & $362 \pm 13$ & $377 \pm 12$ & $1275 \pm 130^{\mathrm{a}}$ \\
\hline
\end{tabular}

Control group and lycopene group received the basal diet. Both iron groups (with or without different doses lycopene) received the basal diet supplemented with ferrous sulfate (1000 mg/kg diet). All animals were fed 0.9\% saline solution by gavage, with or without different doses lycopene (high: $20 \mathrm{mg} / \mathrm{kg}$ body weight; mean: $15 \mathrm{mg} /$ $\mathrm{kg}$ body weight; low: $10 \mathrm{mg} / \mathrm{kg}$ body weight). Treatments lasted for 6 weeks. Results correspond to the means \pm SD of 6 animals. The different pairs of groups were compared using LSD's post hoc test. a $P<0.05$ (vs. control) ; ${ }^{b} P<0.05$ (vs. iron supplementation rats). 
Effect of lycopene administration on serum and tissues iron concentrations

At the end of the 6 weeks treatment, iron supplementation induced a significant increase in iron concentrations in serum, heart, colon $(P<0.01)$, as well as in the liver, spleen in iron treated group $(P<0.05)$ compared with the control group. Iron supplementation had no effect on the kidney iron concentration (Table III). Iron supplementation also induced a significant decrease in serum TIBC $(P<0.01)$ compared with the control group. Lycopene alone did not modify the iron indices except in the liver where a significant decrease $(P<$ 0.01 ) was noticed compared with the control group. Compared with the iron treatment, there was a significant decrease in iron concentration in serum in the iron + lycopene rats $(P<$ $0.01)$, as well as in the spleen $(P<0.01)$ and colon $(P<0.05)$ in the iron + high lycopene rat. Accompanying this finding, a significant increase $(P<0.01)$ was noticed in serum TIBC in the iron + high lycopene and the iron + mean lycopene rats (Table III). Compared with the lycopene alone group, there was a significant increase in iron concentration in serum in the iron + mean lycopene and the iron + low lycopene rats $(P<0.01)$, as well as in liver in the iron + high lycopene and the iron + mean lycopene rats and the colon in the iron + high lycopene rat $(P<$ $0.05)$, but a significant decrease in serum TIBC in the iron + low lycopene rat $(P<0.01)$ and the iron + mean lycopene rat $(P<$ 0.05) (Table III).

\section{Effect of lycopene administration on markers of oxidative stress}

In this study, MDA and T-SOD were used as markers of oxidative damage mediated by iron supplementation. We found that MDA concentration was enhanced by iron supplementation in the liver, heart $(P<0.05)$, as well as in the colon $(P<0.01)$. However, lycopene administration to the iron-treated animals for 6 weeks significantly decreased the MDA concentration in the liver, heart in the iron + high lycopene rat, colon in the iron + high lycopene and the iron + low lycopene rats $(P<0.05)$, as well as in kidney in the iron + high lycopene rat $(P<0.01)$ and moderately in the spleen when compared with iron supplementation animals. Compared with the lycopene alone group, there was a significant increase of the MDA concentration in the liver and colon $(P<0.05)$ in the iron + lycopene groups (Figure 1A-F). Along with this, there was a significant increase in T-SOD activity in the serum $(P<0.01)$ and the liver $(P<0.05)$ by iron supplementation compared with the control group. However, in the heart and colon, antioxidant T-SOD activity decreased $(P<0.01)$ in iron treatment group. Accompanying this finding, a significant decrease was noticed in T-SOD activities in serum in the iron + lycopene groups $(P<0.05)$, but a significant increase $(P<$ $0.05)$ in heart in the iron + high lycopene group and in colon $(P<0.01)$ in the iron + lycopene groups compared with iron supplementation group. In the kidney, only the iron + high lycepone and the iron + mean lycopene groups enhanced the activity of T-SOD $(P<0.05)$. Lycopene alone increased the kidney and the spleen T-SOD activities moderately but not significantly compared with the control group (Figure 2A-F).

Effect of lycopene administration on hepatic structure, cell proliferation and apoptosis

Hematoxylin-eosin stained sections showed no morphological changes. However, Perls' reaction sections showed large amount of iron accumulated in the liver of iron supplementation rats (Figure 3B) compared with the control group (Figure 3A), whereas lycopene treatment reduced the iron staining to a comparable level as in the control or lycopene only groups (Figure 3C, D). Immunohistochemistry analysis showed the number of caspase-3 labelled cells were not changed by the different treatments (Figure 4). In contrast, iron supplementation significantly increased $(P<0.05)$ the number of proliferating hepatocytes and non parenchymal cells $(P<0.05)$ compared with the control group (Figure 5). Interestingly, positive cells were predominantly non parenchymal ones. Consumption of both lycopene and iron increased proliferation in hepatocytes $(P$ $<0.05)$ and non parenchymal cells $(P<0.05)$ compared with the control group, but decreased it $(P<0.05)$ in the non parenchymal cells compared with iron intake alone. Lycopene alone had no effect on the number of Ki-67-positive cells (Figure 5).

TABLE III

The serum and tissues iron status in animals

\begin{tabular}{|c|c|c|c|c|c|c|c|}
\hline $\begin{array}{l}\text { Groups } \\
(n=6)\end{array}$ & $\begin{array}{l}\text { Serum iron } \\
(\mu \mathrm{mol} / \mathrm{L})\end{array}$ & $\begin{array}{c}\text { Liver iron } \\
\text { ( } \mu \mathrm{g} \mathrm{Fe} / \mathrm{g} \\
\text { tissue })\end{array}$ & $\begin{array}{l}\text { Spleen iron } \\
\text { ( } \mu \mathrm{g} \mathrm{Fe} / \mathrm{g} \\
\text { tissue) }\end{array}$ & $\begin{array}{l}\text { Kidney iron } \\
\text { ( } \mu \mathrm{g} \mathrm{Fe} / \mathrm{g} \\
\text { tissue) }\end{array}$ & $\begin{array}{l}\text { Heart iron } \\
\text { ( } \mu \mathrm{g} \mathrm{Fe} / \mathrm{g} \\
\text { tissue) }\end{array}$ & $\begin{array}{c}\text { Colon iron } \\
\text { ( } \mu \mathrm{g} \mathrm{Fe} / \mathrm{g} \\
\text { tissue) }\end{array}$ & $\begin{array}{c}\text { TIBC } \\
(\mu \mathrm{mol} / \mathrm{L})\end{array}$ \\
\hline Control & $16.16 \pm 1.4$ & $25.82 \pm 3.6$ & $46.78 \pm 7.3$ & $19.15 \pm 3.4$ & $15.54 \pm 2.3$ & $10.52 \pm 2.2$ & $58.24 \pm 7.6$ \\
\hline Iron & $36.94 \pm 2.6^{\mathrm{a}^{*}}$ & $29.62 \pm 5.1^{\mathrm{a}}$ & $66.25 \pm 10.1^{\mathrm{a}}$ & $19.42 \pm 4.8$ & $23.03 \pm 3.5^{\mathrm{a}^{*}}$ & $16.15 \pm 3.2^{2^{*}}$ & $32.15 \pm 3.4^{\mathrm{a}^{*}}$ \\
\hline Lycopene & $16.76 \pm 1.6^{b^{*}}$ & $19.57 \pm 2.8^{\mathrm{a}^{*}, \mathrm{~b}^{*}}$ & $48.08 \pm 6.2^{\mathrm{b}}$ & $21.25 \pm 3.9$ & $17.72 \pm 1.8^{\mathrm{b}}$ & $8.15 \pm 1.7$ & $57.68 \pm 8.6^{\mathrm{b}^{*}}$ \\
\hline Iron + High lycopene & $19.06 \pm 2.1^{\mathrm{a}, \mathrm{b}^{*}}$ & $25.67 \pm 2.7^{c}$ & $38.30 \pm 4.8^{\mathrm{b}^{*}}$ & $24.40 \pm 5.1^{\mathrm{a}}$ & $17.30 \pm 2.6$ & $12.08 \pm 2.9^{b, c}$ & $41.68 \pm 7.69^{\mathrm{b}^{*}}$ \\
\hline Iron + Mean lycopene & $21.02 \pm 2.4^{\mathrm{a}^{*}, \mathrm{~b}^{*}, \mathrm{c}^{*}}$ & $25.54 \pm 3.3^{c}$ & $50.51 \pm 5.7$ & $21.05 \pm 3.2$ & $19.20 \pm 3.1$ & $13.12 \pm 2.4$ & $42.36 \pm 8.32^{\mathrm{b}^{*}, \mathrm{c}}$ \\
\hline Iron + Low lycopene & $23.15 \pm 1.7^{\mathrm{a}^{*}, \mathrm{~b}^{*}, \mathrm{c}^{*}}$ & $24.32 \pm 2.9$ & $53.24 \pm 8.1$ & $23.02 \pm 2.7$ & $19.60 \pm 2.7$ & $14.25 \pm 3.7$ & $43.29 \pm 6.73^{\mathrm{a}, \mathrm{c}^{*}}$ \\
\hline
\end{tabular}

Control group and lycopene group received the basal diet. Both iron groups (with or without different doses lycopene) received the basal diet supplemented with ferrous sulfate (1000 mg/kg diet). All animals were fed 0.9\% saline solution by gavage, with or without different doses lycopene (high: $20 \mathrm{mg} / \mathrm{kg}$ body weight; mean: $15 \mathrm{mg} /$ $\mathrm{kg}$ body weight; low: $10 \mathrm{mg} / \mathrm{kg}$ body weight). Treatments lasted for 6 weeks. Results correspond to the means \pm SD of 6 animals. The different pairs of groups were compared using LSD's post hoc test. ${ }^{a^{*} P}<0.01$, a $\boldsymbol{P}<0.05$ (vs. control); ${ }^{b^{*}} \boldsymbol{P}<0.01,{ }^{b} \boldsymbol{P}<0.05$ (vs. iron supplementation rats); ${ }^{c^{*} P}<0.01$, $\boldsymbol{P}^{\boldsymbol{P}}<0.05$ (vs. lycopenetreated rats). 


\section{Ultrastructural alterations and autophagy in liver}

The liver of the control (Figure 6A-B) and lycopene alone treated rats showed few distributed cytoplasmic electrondense particles, typically corresponding to ferritin with more lipid droplets in the lycopene group (Figure 6C). The liver of iron supplementation rats showed large electron-dense bodies localized in the lumen and near the bile canaliculi (BC) forming membrane-encapsulated clusters (Figure 6D) similar to the lysosomes observed in severe conditions of iron overload (Figure 6E) (Gutierrez et al., 2009; Iancu, 1992). The liver of iron supplementation rats also showed the presence of autophagic vacuoles with different shapes and stages containing iron-rich ferritin molecules (Figure 6F). Ultrastructural changes were found in the liver of iron supplementation rats, including mitochondria $(\mathrm{M})$ swelling (Figure 6G), rough endoplasmic reticulum (RER) expanding (Figure 6H). However, in the iron + mean lycopene group, there were more lipid droplets than in the iron supplementation group, and the integrity of the mitochondria membranes was preserved, but microvillus of bile canaliculus reduced (Figure 6I). In addition, iron was accumulated within the hepatic lysosomes where it triggered autophagy as evidenced by the formation of autophagic vesicles detected by LC3-B staining. In agreement with the above detection of autophagosomes by electron microscopy, we observed the characteristic punctuate vesicular staining of LC3-B following iron treatment localized mainly around the portal spaces (Figure 7B). The staining was attenuated in the iron supplementation + mean lycopene group (Figure 7D), and absent in the control and lycopene groups (Figure 7A, C).
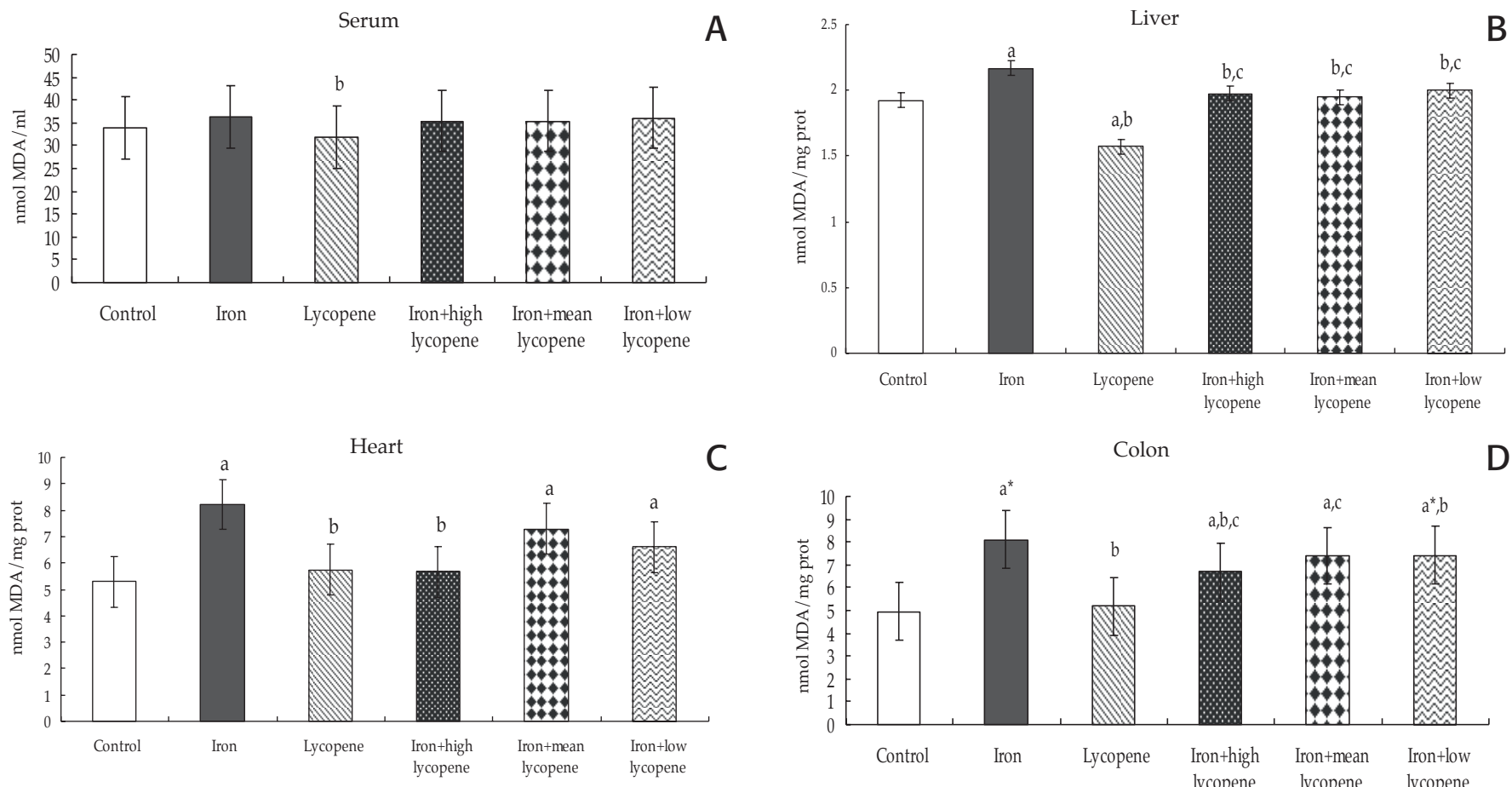

C Colon

D
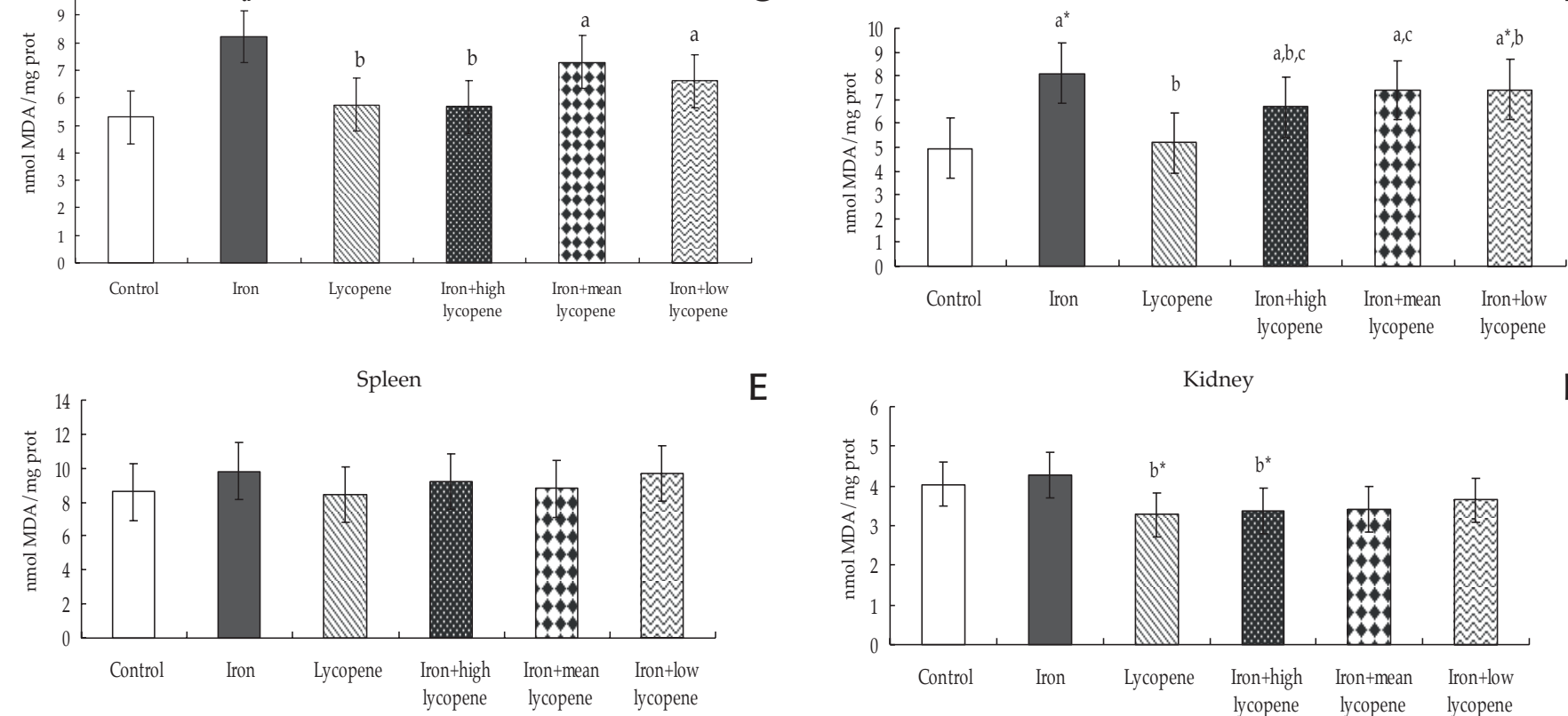

E

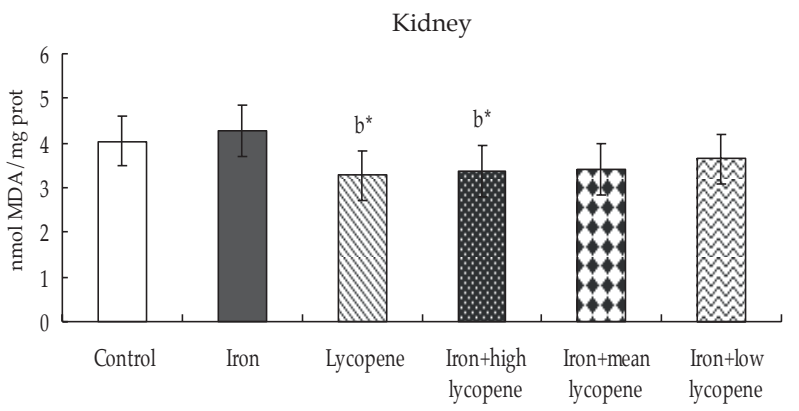

Figure 1 Serum and tissues (Liver, heart, colon, spleen and kidney) MDA content

Control group and lycopene group received the basal diet. Both iron groups (with or without different doses lycopene) received the basal diet supplemented with ferrous sulfate $(1000 \mathrm{mg} / \mathrm{kg}$ diet). All animals were fed $0.9 \%$ saline solution by gavage, with or without different doses lycopene (high: $20 \mathrm{mg} / \mathrm{kg}$ body weight; mean: $15 \mathrm{mg} / \mathrm{kg}$ body weight; low: $10 \mathrm{mg} / \mathrm{kg}$ body weight). Treatments lasted for 6 weeks. Results correspond to the means \pm SD of 6 animals. The different pairs of groups were compared using LSD's post hoc test.

${ }^{a *} P<0.01,{ }^{a} P<0.05$ (vs. control) $;{ }^{b *} P<0.01,{ }^{b} P<0.05$ (vs. iron supplementation rats); ${ }^{c^{*}} P<0.01,{ }^{c} P<0.05$ (vs. lycopene-treated rats). MDA, malondialdehyde. 


\section{DISCUSSION}

This study focused on the effect of lycopene on protection against oxidative damages mediated by nutritional iron supplementation. We also investigated the effect of iron supplementation on apoptosis, proliferation and autophagy in the liver and the capacity of lycopene to reduce these effects at histological and ultrastructural levels. We found that the presence of lycopene in diet offered a protection against lipid peroxidation mediated by iron supplementation. The iron-supplemented liver presented morphological changes associated with proliferation and autophagy but no apoptosis, damages prevented by lycopene pre-treatment.

Dietary intakes of tomatoes and tomato products containing lycopene have been shown to be associated with decreased risk of chronic diseases such as cancer and cardiovascular diseases in several recent studies (Huang and $\mathrm{Hu}, 2011$; Sharma and Goswami, 2011). In this study, we noted the increase in food ingestion observed in rats with lycopene supplementation. The improvement of dietary intake may be due to the fact that lycopene gives the food a special flavour which can increase dietary consumption. Iron excess resulted in an increased oxidative damage in the liver and thus causing mitochondrial membrane alterations. Lipid peroxidation occurred as shown by MDA increase and could thereby change the fluidity of the inner mitochondrial membrane and subsequent mitochondrial swelling, in agreement with previous results (Reifen et al., 2004; Lafay et al., 2005). Such a damage affected especially the liver because it is the major recipient for excessive iron and might indicate a process of iron removal from the liver. Lipid peroxidation also affected the colon, heart, and spleen because these organs accumulated this metal and the colon participated in iron absorption. A recent study showed that the colon iron absorption represented approximately $14 \%$ of the duodenal absorption and that caecal and proximal colon mucosa accumulated iron to a much
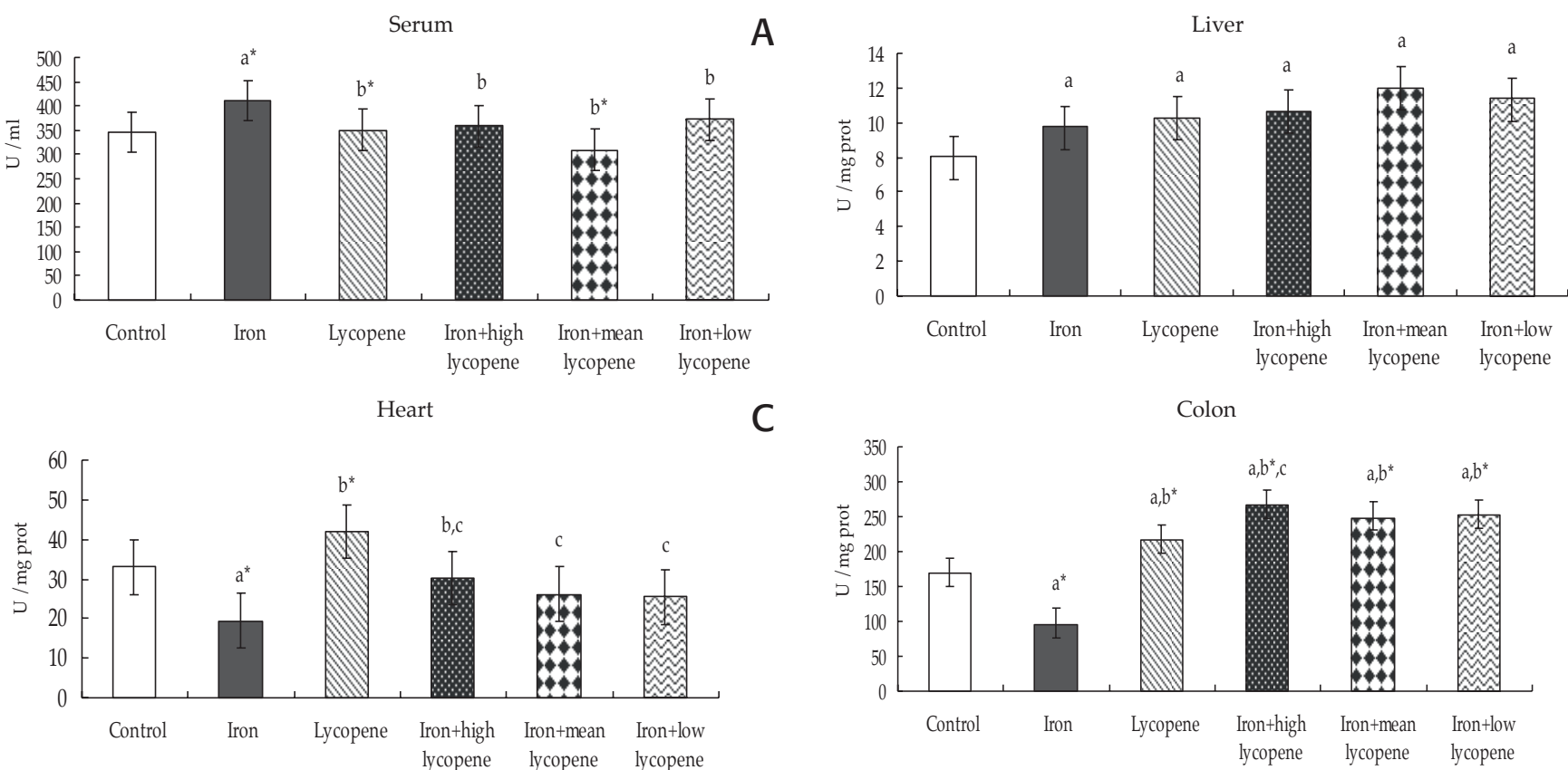

C
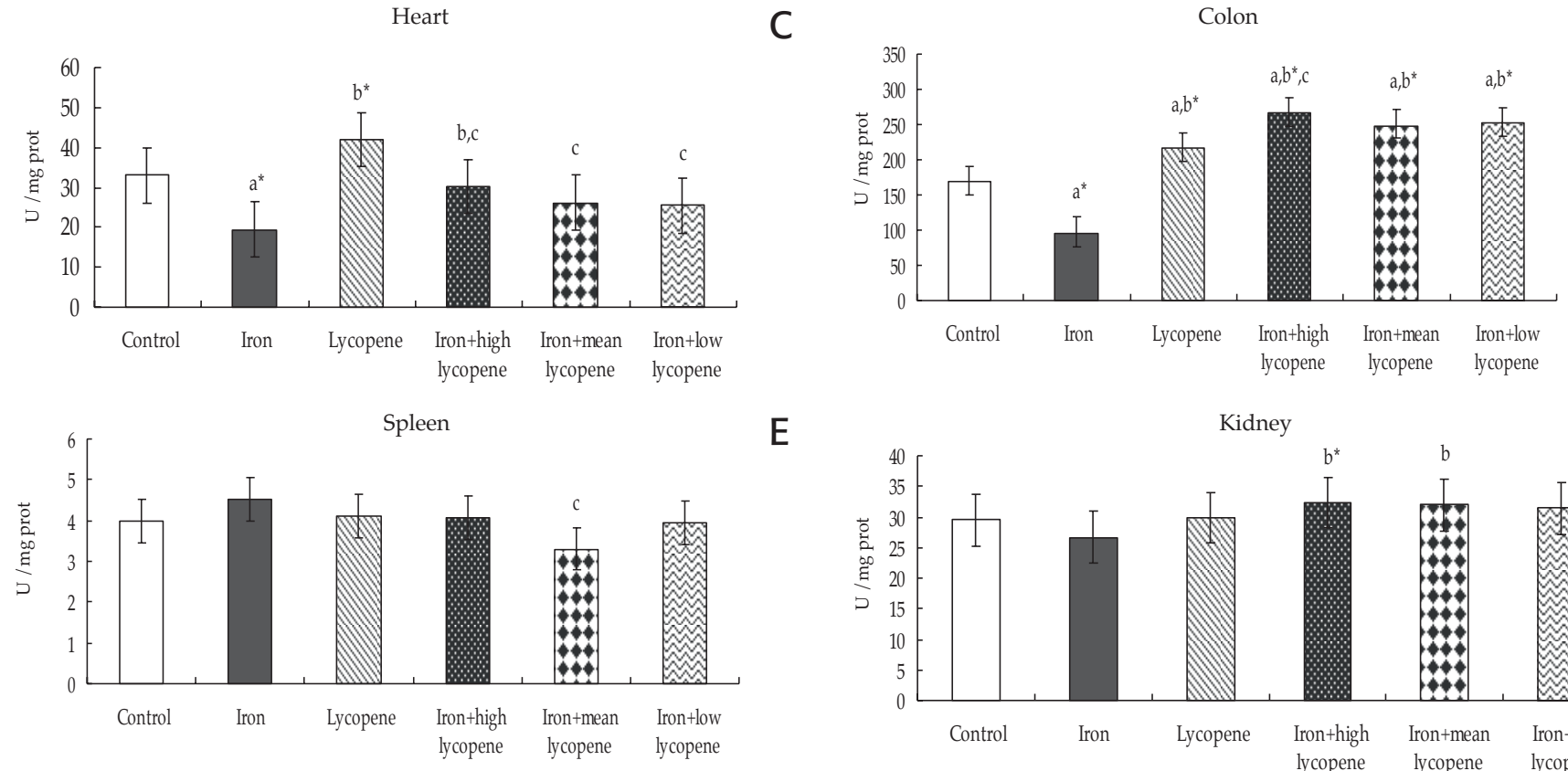

$E$

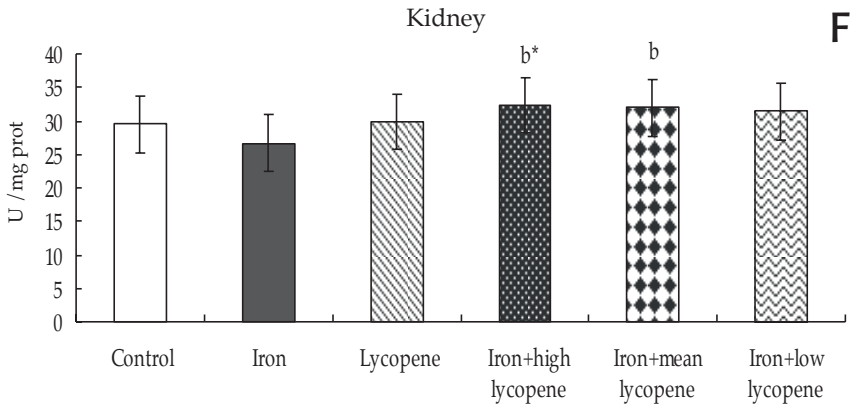

Figure 2 Serum and tissues (Liver, heart, colon, spleen and kidney) T-SOD activity

Control group and lycopene group received the basal diet. Both iron groups (with or without different doses lycopene) received the basal diet supplemented with ferrous sulfate $(1000 \mathrm{mg} / \mathrm{kg}$ diet). All animals were fed $0.9 \%$ saline solution by gavage, with or without different doses lycopene (high: $20 \mathrm{mg} / \mathrm{kg}$ body weight; mean: $15 \mathrm{mg} / \mathrm{kg}$ body weight; low: $10 \mathrm{mg} / \mathrm{kg}$ body weight). Treatments lasted for 6 weeks. Results correspond to the means \pm SD of 6 animals. The different pairs of groups were compared using LSD's post hoc test.

${ }^{a^{*} P}<0.01$, a $P<0.05$ (vs. control) $;{ }^{b *} P<0.01,{ }^{b} P<0.05$ (vs. iron supplementation rats); ${ }^{* *} P<0.01, c P<0.05$ (vs. lycopene-treated rats).

T-SOD, total superoxide dismutase. 

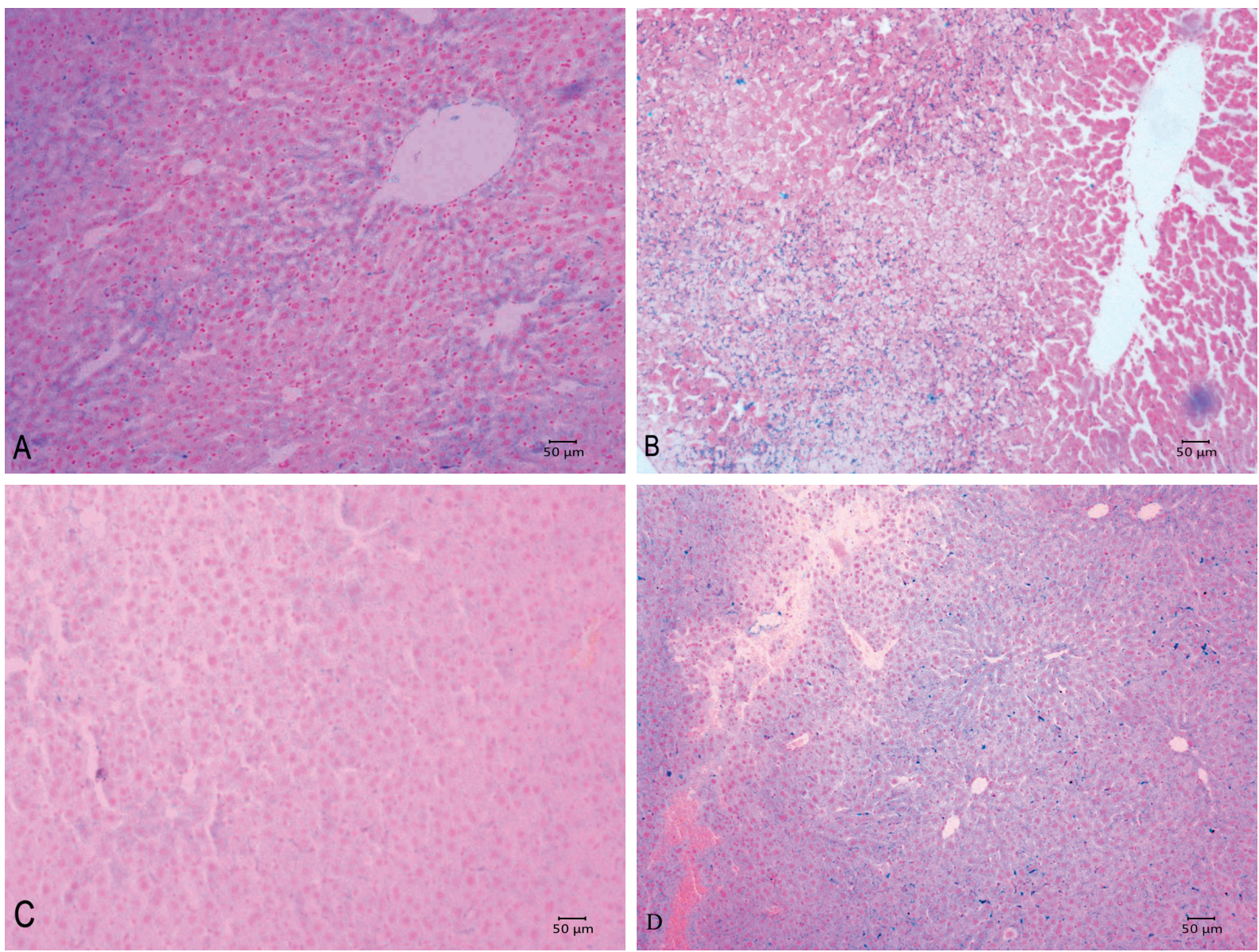

Figure 3 The Perls' reaction and iron accumulation in animals

A. Control group; B. Iron group; C. Lycopene group; D. Iron + mean lycopene group

lower extent than the duodenal mucosa (Blachier et al., 2007). There was no accumulation of iron in kidney suggesting that the kidney might be an efficient way of eliminating excess iron. A recent study demonstrated that the kidney has the ability to express transferrin receptor-1 (TfR1), divalent metal transporter-1 (DMT 1), ferroportin-1 (FPN 1), iron regulatory protein (IRP), hepcidin (Hepc) and other iron metabolism proteins (Veuthey et al., 2008). However, our study also showed that lycopene treatment diminished the electron-dense ferritin storage and protected the mitochondrial membranes. This was confirmed by decreased MDA in the liver and other organs.

An increased serum iron with decreased TIBC in iron group was shown here. When plasma iron concentration exceeds the iron-binding capacity of transferrin, iron accumulates in the body as non-transferrin bound iron and prone to the formation of reactive oxygen species (ROS) and causes cell damages (Papanikolaou and Pantopoulos, 2005; Ghorbel et al., 2011). However, lycopene treatment in the combined group prevented iron-damages by decreasing the level of serum iron and increasing the iron-binding capacity. A previous study showed that garlic alone diminished DMT1 mRNA expression, which decreased the intestinal iron absorption and therefore lowered the iron concentration in the tissues (Nahdi et al., 2010).

Compared with iron supplementation rats, we also found lycopene-treated groups T-SOD activities were enhanced in the heart, colon and kidney, giving evidence of the role of lycopene in scavenging hydroxyl radicals and activating an antioxidant defence enzyme. Interestingly, iron supplementation rats increased hepatic T-SOD activity but decreased it in the colon and heart may be T-SOD behaves towards oxidative stress in two different manners. If stress is sustained and produces massive toxic ROS as shown by the important elevation of the colonic iron concentration, the enzyme will be destroyed and its concentration will decrese (Mena et al., 1991).

The potential of iron damage is particularly high in liver, the primary organ for storage of excess iron. In this study, we found that hepatic iron deposits in rats with iron supplementation compared with the control rats. Immunohistochemical study in the liver showed that iron supplementation did not induce apoptosis but induced proliferation in hepatocytes and non parenchymal cells with a predominance in non parenchymal cells, suggesting an imbalance between these two processes. Caspase-3 may function as the primary executioner in the initiation of apoptosis, and active caspase- 3 may promote apoptosis by degrading key structural and regulatory proteins within the cell. In the combined group, the proliferation rate was intermediate between the control and iron groups suggesting that lycopene reduced the iron mediated proliferation by lowering the iron storage in the liver. Many studies in the liver have demonstrated that chronic iron overload was accompanied by cell proliferation and that it was due to 
the elevation of both cyclin D1 protein and mRNA levels (Brown et al., 2006; Furutani et al., 2006). Excessive ROS production can lead to oxidation of macromolecules and has been implicated in mtDNA mutations, ageing, and cell death. Mitochondria-generated ROS play an important role in the release of cytochrome $\mathrm{c}$ and other proapoptotic proteins, which can trigger caspase activation and apoptosis. Other studies reported that Fe-NTA could lead to oxidative stress and apoptosis in hepatocyte cultures (Walter et al., 2002; Rauen et al., 2004).

Our results showed that ferritin deposits in the liver of iron supplementation rats were dispersed in the cytoplasm
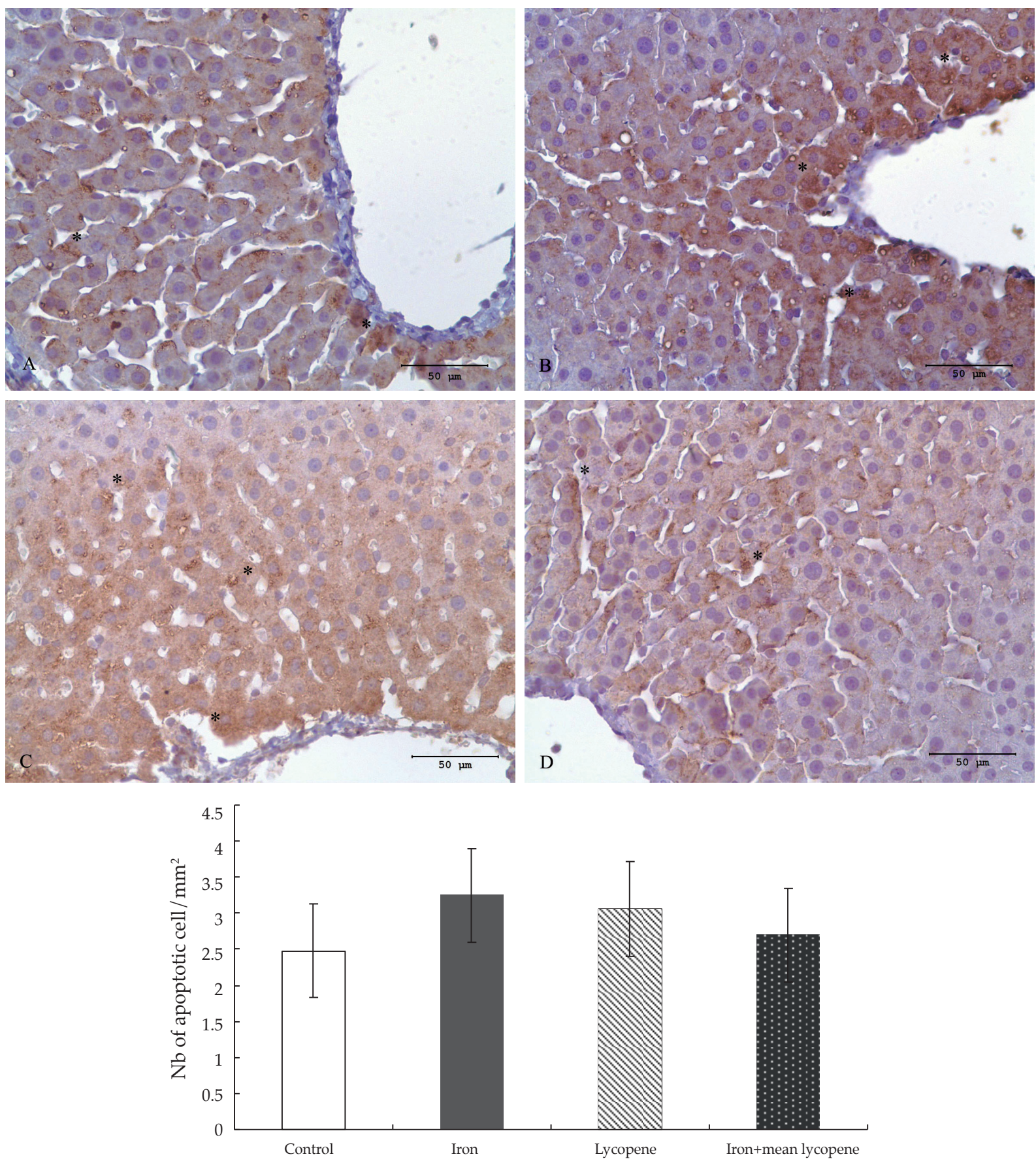

\section{Figure 4 Detection of apoptosis in the liver of rats}

(The mouse anti-active caspase-3 monoclonal antibody (1:50) was used) A. Control group; B. Iron group; C. Lycopene group; D. Iron + mean lycopene group. Control group and lycopene group received the basal diet. Both iron groups (with or without lycopene) received the basal diet supplemented with ferrous sulfate $(1000 \mathrm{mg} / \mathrm{kg}$ diet). All animals were fed $0.9 \%$ saline solution by gavage, with or without lycopene $(15 \mathrm{mg} / \mathrm{kg}$ body weight). Treatments lasted for 6 weeks. *Representative active caspase-3 immunohistochemistry for the detection of apopotic cells in the liver of rats showed coloured zones in the cytoplasm. Number of apoptotic cells counted in 100 fields per group and expressed per $\mathrm{mm}^{2}$. Results correspond to the means \pm SD of 6 animals. 
of cells or localized in lysosomes mainly near the bile canaliculi, in agreement with previous results (Gutierrez et al., 2009). We also demonstrated that iron supplementation was accompanied by activation of autophagy, an adaptive mechanism to cell damages. However, iron + lycopene groups diminished the electron-dense ferritin storage, protected the mitochondrial membranes and reduced punctuated LC3-B staining compared with iron group. The autophagic vesicles were barely detectable in control, lycopene treated and iron
+ lycopene treated groups. Autophagy is a housekeeping process that ensures the turnover of damaged protein aggregates and organelles to maintain cell homeostasis (Xie and Klionsky, 2007). Lysosomes are central in autophagy as they fuse with autophagosomes to form autophagolysosomes where a variety of organelles and proteins are degraded via their acid hydrolases. Therefore, the lysosomal membrane peroxidation takes place and lysosomes become leaky after a delay that is dependent on the magnitude of oxidative stress.
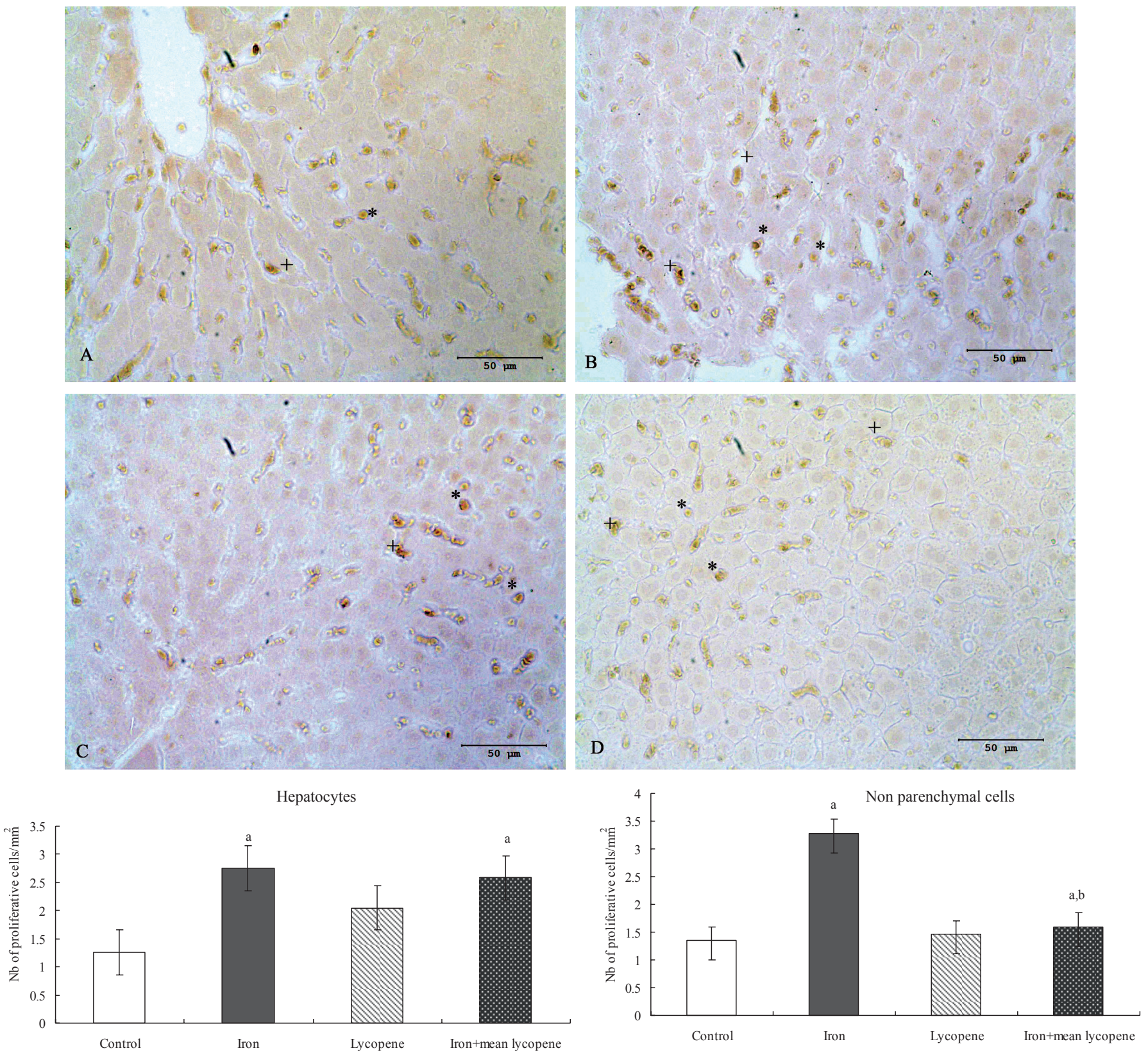

Figure 5 Detection of proliferation in the liver of rats

A. Control group; B. Iron group; C. Lycopene group; D. Iron+mean lycopene group. Control group and lycopene group received the basal diet. Both iron groups (with or without lycopene) received the basal diet supplemented with ferrous sulfate (1000 mg/kg diet). All animals were fed $0.9 \%$ saline solution by gavage, with or without lycopene $(15 \mathrm{mg} / \mathrm{kg}$ body weight). Treatments lasted for 6 weeks. Representative Ki-67 immunohistochemistry for the detection of proliferation cells in the liver of the rats showed brown immunostained nuclei in hepatocytes $(*)$ and in non-parenchymal cells $(+)$. Number of proliferation cells in hepatocytes and in non-parenchymal cells counted in 100 fields per group and expressed per $\mathrm{mm}^{2}$. Results correspond to the means \pm SD of 6 animals. a $P<0.05$ (vs. control) ; b $P<0.05$ (vs. iron overload rats). 

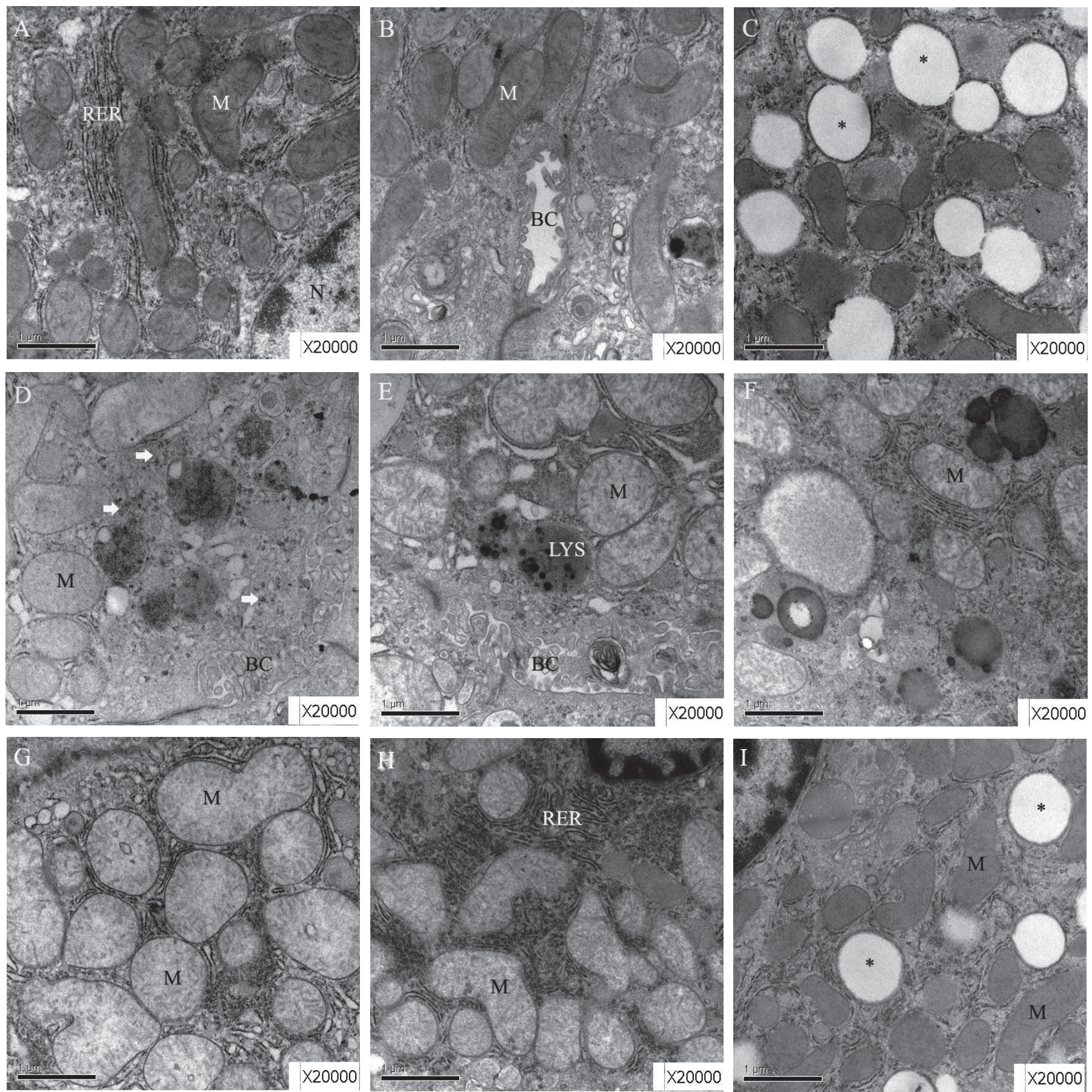

\section{Figure 6 Ultrastructural alterations in the liver}

A-B. Control group; C. Lycopene group; D-H. Iron group; I. Iron + mean lycopene group. Representative transmission electron micrographs of control and treated groups in liver showed an accumulation of many lipid droplets $\left(^{*}\right)$ in the lycopene group. The liver of iron supplementation rats showed iron-rich ferritin localized in the lumen and near the bile canaliculus (BC) along with lysosomes ( $\rightarrow$, Fig. 6D), mitochondria (M) swelling (Fig. 6G), rough endoplasmic reticulum (RER) expanding (Fig. 6H), autophagosomes with different shapes and stages dispersed in the cytoplasm (Fig. 6F). In the iron + mean lycopene group, the integrity of mitochondria membranes was preserved (Fig. 6l). 

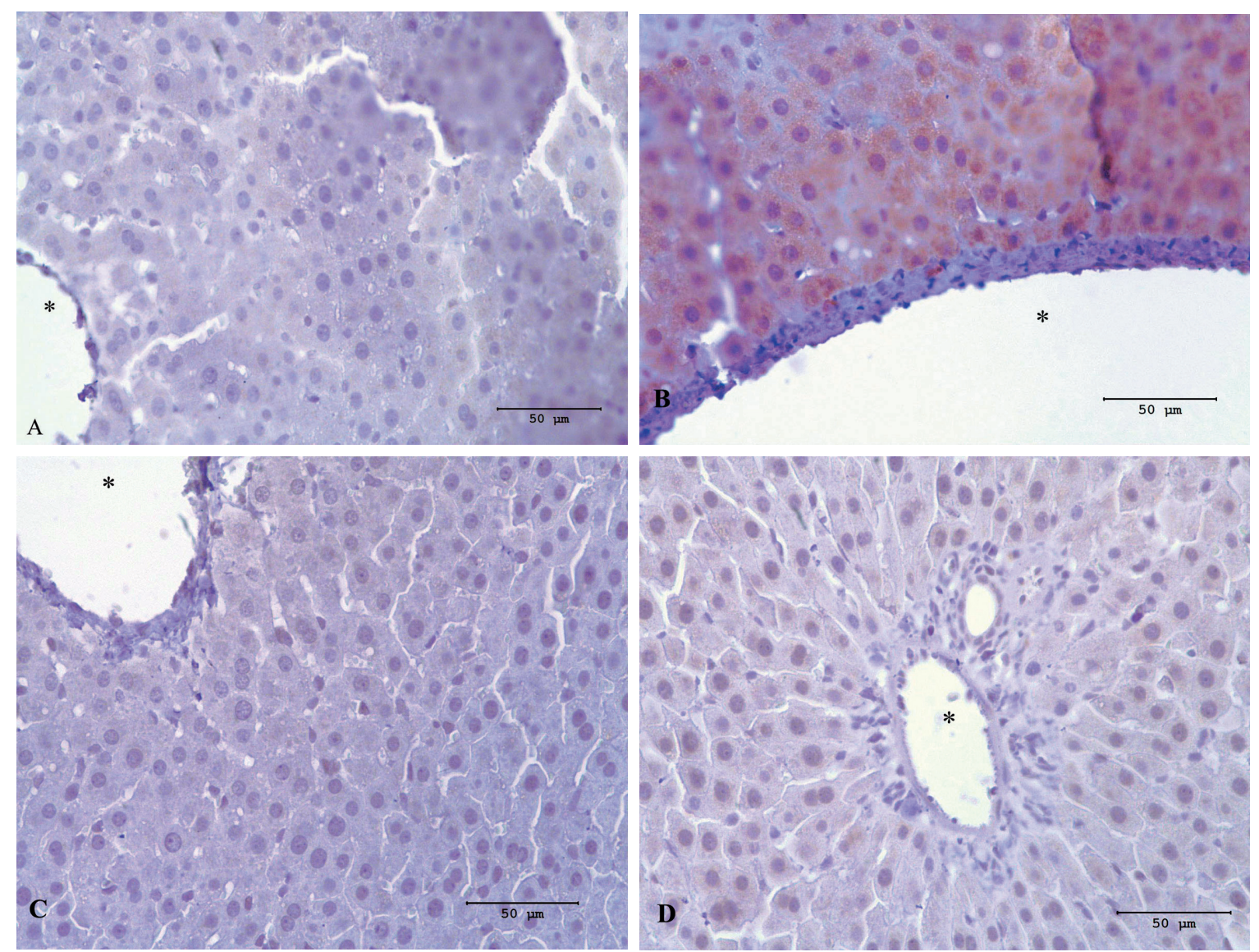

\section{Figure 7 Detection of autophagy in the liver of rats}

A. Control group; B. Iron group; C. Lycopene group; D. Iron + mean lycopene group. Representative LC3-B immunohistochemistry for the detection of autophagy in the liver of the control and treated groups showed punctuated vesicular staining following iron treatment mainly localized around the portal spaces. (*portal vein branch). The staining was attenuated in the iron + mean lycopene group and absent in the control and lycopene group, but punctuated vesicular staining of LC3-B in the iron supplementation rats.

This is followed by reparative autophagy which is an early defence mechanism of the cell (Antunes et al., 2001). Our study demonstrated an unexpected early upregulation of autophagy and proliferation in response to iron supplementation. Autophagy can provide an early adaptive mechanism avoiding apoptosis. Lycopene significantly prevented iron-mediated oxidative stress in the liver and colon and iron-induced mitochondrial alteration and autophagy in the liver due to its potent free radical scavenging and antioxidant properties.

\section{ACKNOWLEDGMENT}

The authors thank all reviewers and Prof. P.H. Backx (University of Toronto, Canada) and Prof. Z.M. Qian (The Hong Kong Polytechnic University, China) for critical reading. We are grateful to the Zhejiang Province Natural Sciences Foundation (Y2110388) and Zhejiang Province Technological Research (Y2011C37091) for financial support.

\section{REFERENCES}

ANDREWS NC (1999) Disorders of iron metabolism. N Engl J Med 341: 19861995.

ANDREWS NC, SCHMIDT PJ (2007) Iron homeostasis. Annu Rev Physiol 69: 69-85.
ANTUNES F, CADENAS E, BRUNK UT (2001) Apoptosis induced by exposure to a low steady-state concentration of $\mathrm{H}_{2} \mathrm{O}_{2}$ is a consequence of lysosomal rupture. Biochem J 356: 549-555.

BLACHIER F, VAUGELADE P, ROBERT V, KIBANGOU B, CANONNEHERGAUX F, DELPAL S (2007) Comparative capacities of the pig colon and duodenum for luminal iron absorption. Can J Physiol Pharmacol 85: 185-192.

BOSE KS, AGRAWAL BK (2007) Effect of lycopene from tomatoes (cooked) on plasma antioxidant enzymes, lipid peroxidation rate and lipid profile in grade-I hypertension. Ann Nutr Metab 51: 477-481.

BRADFORD MM (1976) A rapid and sensitive method for the quantitation of microgram quantities of protein utilizing the principle of protein-dye binding. Anal Biochem 72: 248-254.

BROWN KE, MATHAHS MM, BROADHURST KA, WEYDERT J (2006) Chronic iron overload stimulates hepatocyte proliferation and cyclin D1 expression in rodent liver. Transl Res 148: 55-62.

DAIRAM A, FOGEL R, DAVA S, LIMSON JL (2008) Antioxidant and ironbinding properties of curcumin, and s-allylcysteine reduce oxidative stress in rat brain homogenate. J Agric Food Chem 56: 3350-3356.

EATON JW, QIAN M (2002) Molecular bases of cellular iron toxicity. Free Radic Biol Med 32: 833-840.

FURUTANI T, HINO H, OKUDA M, GONDO T, NISHINA S, KITASE A (2006) Hepatic iron overload induces hepatocellular carcinoma in transgenic mice expressing the hepatitis $\mathrm{C}$ virus polyprotein. Gastroenterology 130: 2087-2098.

GALLUZZI L, MAIURI MC, VITALE I, ZISCHKA H, CASTEDO M, ZIVOGEL L (2007) Cell death modalities: classification and pathophysiological implications. Cell Death Differ 14: 1237-1243. 
GAO X, CAMPIAN JL, QIAN M, SUN XF, EATON JW (2009) Mitochondrial DNA damage in iron overload. J Biol Chem 284: 4767-4775.

GARCÍA ALONSO FJ, JORGE VIDAL V, ROS G, PERIAGO J (2011) Effect of consumption of tomato juice enriched with n-3 polyunsaturated fatty acids on the lipid profile, antioxidant biomarker status, and cardiovascular disease risk in healthy women. Eur J Nutr 14: 394-403.

GARNER B, LI W, ROBERG K (1997) On the cytoprotective role of ferritin in macrophages and its ability to enhance lysosomal stability. Free Radic Res 27: 487-500.

GARNER B, LI W, ROBERG K, BRUNK UT (1997) Endogenous ferritin protects cells with iron-laden lysosomes against oxidative stress. Free Radic Res 29: 103-114.

GARRICK MD (2011) Human iron transporters. Genes Nutr 6: 45-54

GHORBEL H, FEKI I, FRIHA I, KHABIR AM, BOUDAWARA T, BOUDAWARA M (2011) Biochemical and histological liver changes occurred after iron supplementation and possible remediation by garlic consumption. Endocr 5: 948-957.

GUTIÉRREZ L, QUINTANA C, PATINO C, BUENO J, COPPIN H, ROTH MP (2009) Iron speciation study in Hfe knockout mice tissues: Magnetic and ultrastructural characterisation. Biochim Biophys Acta 1792: 541-547.

HUANG CS, HU ML (2011) Lycopene inhibits DNA damage and reduces hMTH1 mRNA expression in the liver of Mongolian gerbils treated with ferric nitrilotriacetate. Food Chem Toxicol 496: 1381-1386.

IANCU TC (1992) Ferritin and hemosiderin in pathological tissues. Electron Microsc Rev 5: 209-229.

IANCU TC (2011) Ultrastructural aspects of iron storage, transport and metabolism. J Neural Transm118: 329-335.

KAUR H, CHAUHAN S, RAJAT SR (2011) Protective effect of lycopene on oxidative stress and cognitive decline in rotenone induced model of Parkinson's disease. Neurochem Res 36: 1435-1443.

KURZ T, TERMAN A, BRUNK UT (2007) Autophagy, ageing and apoptosis: the role of oxidative stress and lysosomal iron. Arch Biochem Biophys 462: $220-230$.

LAFAY S, GUEUX E, RAYSSIGUIER Y, MAZUR A, REMESY C, SCALBERT A (2005) Caffeic acid inhibits oxidative stress and reduces hypercholesterolemia induced by iron overload in rats. Int J Vitam Nutr Res 75: 119-125.
LYOUMI S, ABITBOL M, ANDRIEU V, HENIN D, ROBERT E, SCHMITT C (2007) Increased plasma transferrin, altered body iron distribution, and microcytic hypochromic anemia in ferrochelatase-deficient mice. Blood 109: 811-818.

MENA P, MAYNAR M, GUTIÉRREZ JM, MAYNAR J, TIMON J, CAMPILLO JE (1991) Erythorcyte free radical scavenger enzymes in bicycle professional racers. Adaptation to training. Int J Sports Med 12: 563-566.

MORIHARA N, SUMIOKA I, IDE N, MORIGUCHI T, UDA N, KYO E (2006) Aged garlic extract maintains cardiovascular homeostasis in mice and rats. J Nutr 136: S777-S781.

NAHDI A, HAMMAMI I, BRASSELAGNEL C, PILARD D, HAMDAOUI MH, BEAUMONT C (2010) Influence of garlic or its main active component dially1 disulfide on iron bioavailability and toxicity. Nutr Res 30: 85-95.

NAHDI A, HAMMAMI I, KOUIDHI W, CHARGUI A, BENAMMAR A HAMDAOUI MH (2010) Protective effects of crude garlic by reducing iron-mediated oxidative stress, proliferation and autophagy in rats. J Mol Hist 41: 233-245.

PAPANIKOLAOU G, PANTOPOULOS K (2005) Iron metabolism and toxicity. Toxicol Appl Pharmacol 202: 199-211.

RAUEN U, PETRAT F, SUSTMANN R, DEGROOT H (2004) Iron-induced mitochondrial permeability transition in cultured hepatocytes. J Hepatol 40: 607-615.

REIFEN R, NISSENKORN A, MATAS Z, BUJANOVER Y (2004) 5-ASA and lycopene decrease the oxidative stress and inflammation induced by iron in rats with colitis. J Gastroenterol 39: 514-519.

SHARMA N, GOSWAMI UC (2011) Functioning of lycopene in mammalian system: a review. Proc Zool Soc 64: 1-7.

VEUTHEY T, D' ANNA, ROQUE ME (2008) Role of the kidney in iron homeostasis: renal expression of prohepcidin, ferroportin, and DMT1 in anemic mice. Am J Physiol Renal Physiol 295: F1213-1221.

WALTER PB, KNUTSON MD, PALERMARTINEZ A, LEE S, XU Y, VITERI FE (2002) Iron deficiency and iron excess damage mitochondria and mitochondrial DNA in rats. Proc Natl Acad Sci 99: 2264-2269.

XIE Z, KLIONSKY DJ (2007) Autophagosome formation: core machinery and adaptations. Nat Cell Biol 9: 1102-1109. 